\title{
Pemanfaatan Limbah Carsul Sebagai Koagulan Untuk Menurunkan Konsentrasi Chrome Hexavalent Dalam Air Limbah Industri Nikel.
}

\author{
Muhammad Muzammil Ikmal ${ }^{1}$, Mery Selintung ${ }^{2}$, dan Rosalinda Ibrahim, ${ }^{3,4}$ \\ ${ }^{1,2,3}$ Departemen Teknik Lingkungan Fakultas Teknik Universitas Hasanuddin, Indonesia \\ ${ }^{4}$ Institut Teknologi Sepuluh November \\ Imuh.zammil01@gmail.com, ${ }^{2}$ mary.selintung@yahoo.com, ${ }^{3}$ linda_lingk09@yahoo.co.id
}

\begin{abstract}
Abstrak
Kata Kunci

Air Limbah; Carsul; Chrome Hexavalent; Koagulan; Tambang.

Pertambangan merupakan suatu kegiatan yang berhubungan dengan lingkungan. Pertambangan nikel di Sorowako yang saat dipegang oleh PT. Vale Indonesia, Tbk, Salah satu limbah yang dihasilkan pada kegiatan penambangan bijih nikel berupa Carsul yang berasal dari sulphur melter yang merupakan sumber mineral yang dapat diolah kembali. Tujuan penelitian ini adalah untuk mengetahui besar kandungan Chrome Hexavalent dalam air limbah hasil produksi tambang nikel PT. Vale Indonesia, Tbk. dan menganalisis pengaruh massa koagulan (Carsul) serta lama waktu pengadukan terhadap efisiensi penyisihan Chrome Hexavalent dalam air limbah tambang nikep PT. Vale Indonesia. Tbk. Metodologi yang digunakan adalah kuantitatif eksperimen. Hasil penelitian menunjukkan kandungan air limbah hasil produksi PT. Vale Indonesia, Tbk 0,2 ppm, adapun massa koagulan yang paling efektif adalah 5gram dengan rata-rata efisiensi penyisihan Chrome Hexavalent sebesar 98,5\%, dan lama waktu pengadukan optimum adalah 20 detik dengan rata-rata efisiensi penyisihan Chrome Hexavalent sebesar 97,2\%. Berdasarkan nilai penyisihan kadar Chrome Hexavalent oleh Carsul sebagai koagulan cukup memberikan pengaruh positif dan cukup efektif.
\end{abstract}

Keywords

Carsul; Coagulant; Chrome Hexavalent Mining,

Wastewater.

\begin{abstract}
Mining is an activity related to the environment. Nickel mining in Sorowako, which was currently held by PT. Vale Indonesia, Tbk, One of the wastes generated in nickel ore mining activities is Carsul which comes from sulfur melter which is a mineral source that can be reprocessed. The purpose of this study was to determine the content of Chrome Hexavalent in the waste water produced by the nickel mine of PT. Vale Indonesia, Tbk. and to analyze the effect of coagulant mass (Carsul) and the length of time of stirring on the removal efficiency of Chrome Hexavalent in PT. Vale Indonesia. Tbk. The methodology used is quantitative experiment. The results showed that the content of waste water produced by PT. Vale Indonesia, Tbk 0.2ppm, while the most effective coagulant mass is 5 grams with an averageremoval efficiency Chrome Hexavalent of 98.5\%, and the optimum stirring time is 20 seconds with an averageremoval efficiency Chrome Hexavalent of 97.2. \%. Based on the removal value oflevels Chrome Hexavalent by Carsul as a coagulant, it was quite positive and quite effective.
\end{abstract}

\section{PENDAHULUAN}

Secara berkelanjutan PT. Vale Indonesia, Tbk. terus mengembangkan pengelolaan dan pengolahan limbah dari kegiatan operasi pertambangan maupun produksi nikel dalam matte. Salah satu limbah yang dihasilkan pada kegiatan penambangan bijih nikel berupa Carsul yang berasal dari sulphur melter yang merupakan sumber mineral yang dapat diolah kembali. Saat ini Carsul belum digunakan secara internal oleh PT. Vale Indonesia Tbk. Dengan kandungan 88\% Sulfur, 11\% Cao, 
dan $1 \%$ Fe serta Mn dalam Carsul maka bisa di lakukan cara untuk mendaur ulang bahan tersebut menjadi produk baru.

Pada air limbah hasil produksi tambang nikel selalu menghasilkan produk samping ataupun zat sisa yang berupa padatan maupun cair hal tersebut pasti terjadi dalam proses pemecahan bongkahan untuk mendapatkan inti nikel di dalamnya. Hal tersebut biasa dilakukan dalam proses Pressing Machine yang dimana pada proses ini bertujuan untuk memecah bongkahan agar nikel yang berada di dalam bongkahan tersebut dapat di ambil, atau merupakan proses pemisaha antara nikel dan bongkahan yang melengket dengan nikel tersebut.

Dari hasil observasi yang telah dilakukan bagian internal PT. Vale Indonesia, Tbk berusaha untuk mencari cara untuk memanfaatkan produk sampingan dari hasil Pressing Machine berupa Carsul untuk menjadi hal yang lebih bermanfaat dan bernilai menyelamatkan lingkungan dari tercemarnya karena produk samping dari hasil proses pertambangan nikel PT. Vale Indonesia, Tbk (Palippui, 2020).

Salah satu metode yang dapat digunakan untuk menganalisis efektivitas pengelolaan lingkungan adalah menguji efisiensi penyisihan Chrome Hexavalent yang berada di dalam air limbah tambang PT. Vale Indonesia, Tbk, sebuah metode pengukuran yang bertujuan untuk mengetahui nilai manfaat dari sebuah kegiatan dilihat dari sudut pandang secara keseluruhan (Fitrianto dkk, 2021) .

Salah satu metode yang dapat digunakan untuk menganalisis efektivitas pengelolaan lingkungan adalah menguji efisiensi penyisihan Chrome Hexavalent yang berada di dalam air limbah tambang PT. Vale Indonesia, Tbk, sebuah metode pengukuran yang bertujuan untuk mengetahui nilai manfaat dari sebuah kegiatan dilihat dari sudut pandang secara keseluruhan.

Penelitian ini bertujuan untuk mengetahui besar kandungan Chrome Hexavalent dalam air limbah hasil produksi tambang nikel, menganalisis pengaruh massa koagulan Carsul terhadap efisiensi penyisihan Chrome Hexavalent dalam air limbah tambang nikel dan menganalisis pengaruh lama waktu pengadukan terhadap efisiensi penyisihan Chrome Hexavalent dalam air limbah tambang nikel PT. Vale Indonesia, Tbk.

\section{TINJAUAN PUSTAKA}

Senyawa koagulan adalah senyawa yang mempunyai kemampuan mendestabilisasi koloid dengan cara menetralkan muatan listrik pada permukaan koloid sehingga koloid dapat bergabung satu sama lain membentuk flok dengan ukuran yang lebih besar sehingga mudah mengendap (Astutia, 2020).

Carsul sebagai by product dari proses Sulfur Melter merupakan sumber mineral yang dapat diolah kembali. Adapun kandungan Carsul adalah: Sulhphur 88\%, Cao 11\%, Fe \& Mn 1\%. Saat ini Carsul belum digunakan secara internal oleh PT. Vale Indonesia, Tbk. Dengan kandungan $88 \%$ Sulfur maka bisa dilakukan cara untuk mendaur ulang bahan tersebut menjadi produk baru (Vale, 2020).

Limbah Cr(VI) menjadi populer mengingat sifatnya yang tidak mudah terurai di alam dan karsinogenik. Logam kromium tersebut terdapat di alam dalam dua bentuk oksida, yaitu oksida $\mathrm{Cr}(\mathrm{III})$ dan $\mathrm{Cr}(\mathrm{VI})$. Daya racun yang dimiliki kromium ditentukan oleh bilangan oksidasinya. Uniknya hanya $\mathrm{Cr}$ (VI) yang bersifat karsinogenik sedangkan $\mathrm{Cr}$ (III) tidak (Said, 2018). Hal ini karena sifatnya yang berdaya larut dan mobilitas tinggi di lingkungan (Blessing dkk, 2020) (Zamil, 2021).

Umumnya pengolahan limbah cair yang mengandung bahan berbahaya seperti logam berat dapat dilakukan secara kimia Pengolahan ini termasuk reaksi redoks (reduksi-oksidasi). Beberapa upaya pengolahan limbah $\mathrm{Cr}(\mathrm{VI})$ yang telah dilakukan seperti bioreduksi, ion exchange, adsorpsi dengan karbon aktif dan reduksi dengan bantuan bakteri, dimana memiliki kelemahan yaitu diperlukannya 
energi yang sangat tinggi dan/atau bahan kimia yang sangat banyak. Karenanya pengolahan limbah $\mathrm{Cr}(\mathrm{VI})$ memerlukan biaya yang cukup besar sehingga perlu dilakukan pengolahan alternatif lain dengan biaya yang relatif lebih murah dan efektif (Fasya, 2018) (Lestari dkk, 2019).

Limbah cair (effluent) yang dihasilkan dari operasi penambangan dan pengolahan bijih nikel diolah untuk mengurangi kandungan total padatan tersuspensi (TSS) dan Chromium $(\mathrm{Cr} 6+)$. PT. Vale Indonesia Tbk, berkomitmen untuk mengolah limbah cair tersebut agar memenuhi standar kualitas sebelum dikembalikan ke badan air (Vale, 2017).

\section{METODOLOGI PENELITIAN}

Pada penelitian ini digunakan jenis penelitian bersifat ekperimen kuantitatif yaitu penelitian yang dilakukan untuk mengetahui Efektifitas Carsul dalam menurunkan kadar Chrome Hexavalent pada air hasil produksi PT. Vale Indonesia, Tbk. Penelitian ini terdiri dari dua variable yaitu:

1. Variabel bebas yaitu massa koagulan Carsul, dan lama waktu pengadukan.

2. Variabel terikat yaitu kadar konsentrasi Chrome Hexavalent.

Adapun variabel massa Carsul terdiri dari 5 variasi yaitu 5 gram, 10 gram, 20 gram, 30 gram, dan 40 gram. sedangkan variabel lama waktu pengadukan terdiri dari 4 variasi yaitu 20 detik, 30 detik, 60 detik, dan 90 detik.

\subsection{Waktu dan Lokasi Penelitian}

Penelitian skala laboratorium dilaksanakan di laboratorium Kualitas Air, Departemen Teknik Lingkungan, Fakultas Teknik, Universitas Hasanuddin, dengan mengambil sampel dari PT. Vale Indonesia, Tbk. Sedangkan untuk waktu penelitian dilaksanakan mulai dari minggu pertama tanggal 4 di bulan Januari 2021 hingga pekan terakhir di bulan Maret 2021, pada waktu tersebut penelitian dilakukan dengan skala uji laboratorium mulai dari persiapan alat, kemudian bahan, hingga proses pengadukan serta pengujian dan analisis data.

\subsection{Alat dan Bahan}

Alat yang digunakan dalam penelitian ini ialah cawan, gelas ukur 50ml, gelas ukur $1000 \mathrm{ml}$, tabung reaksi, pipet tetes $20 \mathrm{ml}$, pipet tetes $50 \mathrm{ml}$, pipet tetes $100 \mathrm{ml}$, neraca analitik, kertas $\mathrm{Ph}$, pengaduk kaca, Floculator, Stopwatch dan $U V$-Vis. Bahan yang digunakan dalam penelitian ini ialah, Carsul, Air hasil Produksi PT. Vale Indonesia, Tbk, asam Phospat, Defenilcarbazida, dan Aquades.

\subsection{Populasi dan Sampel}

Populasi dalam penelitian ini menggunakan Carsul dari air limbah yang dihasilkan dari PT. Vale Indonesia, Tbk. Sampel yang digunakan sebagai objek pada penelitian ini ialah Carsul dan air limbah yang mengandung Chrome Hexavalent $\left(\mathrm{Cr}^{+}\right)$dengan kadar 0,2 ppm dari PT. Vale Indonesia, Tbk.

\section{HASIL DAN PEMBAHASAN}

\section{Kandungan Chrome Hexavalent Dalam Air Limbah Tambang Nikel}

Pada penelitian ini data awal yang di dapatkan ialah kandungan Chrome Hexavalent pada air limbah tambang nikel PT. Vale Indonesia, Tbk, Kadar kandungan Chrome Hexavalent diketahui melalui pengujian menggunakan alat $U V$-Vis sebagai alat untuk mengetahui kadar Chrome Hexavalent.

Kadar kandungan Chrome Hexavalent pada air limbah tambang nikel melalui pengujian $U V$-Vis ialah $0.2 \mathrm{ppm}$, dan hal tersebut tidak memenuhi standar baku mutu dari PERMENLH No.5 Tahun 2014 mengenai standar baku mutu untuk Chrome Hexavalent $\left(\mathrm{Cr}^{+}{ }^{+}\right)$adalah $0,1 \mathrm{ppm}$. 


\section{Pengaruh Massa Koagulan Carsul Terhadap Efisiensi Penyisihan Chrome Hexavalent Dalam Air Limbah Tambang Nikel}

Carsul yang digunakan merupakan koagulan tunggal yang berfungsi untuk menurunkan kadar konsentrasi Chrome Hexavalent dalam air limbah tambang nikel PT. Vale Indonesia, Tbk. Variasi jumlah massa koagulan ialah 5g, 10g, 20g, 30g, dan 40g. variasi jumlah massa koagulan yang di tentukan hampir sama dengan variasi jumlah koagulan yang dilakukan pada penelitian Winarni.,dkk (2011) Penelitian dilakukan secara batch dalam skala laboratorium dengan menggunakan jar-test, yang merupakan simulasi operasional proses pengolahan konvensional. Jar-test dilakukan pada 2 replikat untuk tiap seri jar-test, dimana dalam 1 seri dilakukan pada kecepatan putaran dan waktu pengadukan yang konstan dengan variasi dosis koagulan.

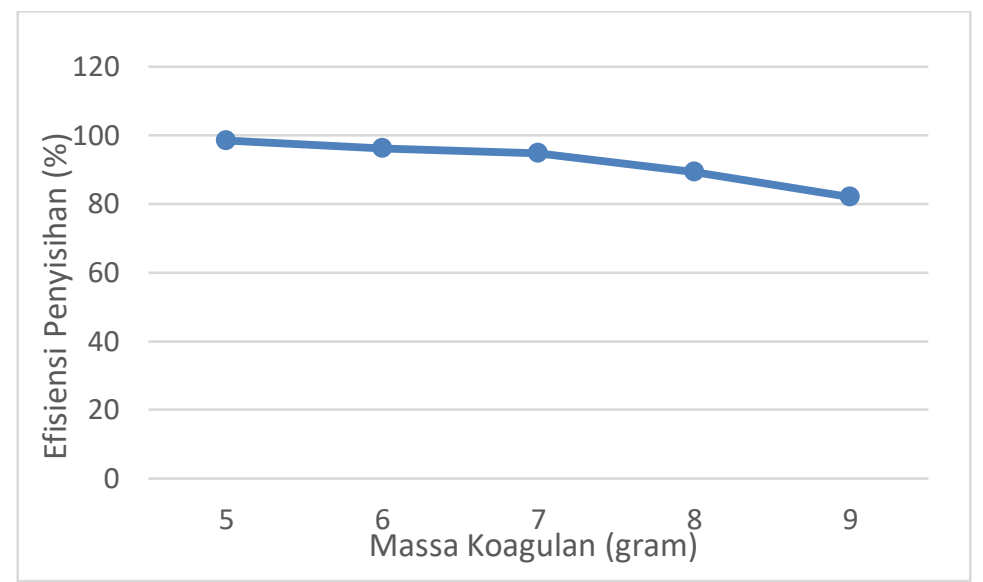

Gambar 1. Grafik hubungan antara massa koagulan dengan efisiensi penyisihan Chrome Hexavalent.

Berdasarkan grafik tersebut dapat dilihat bahwa hubungan antara massa koagulan dengan efisiensi penyisihan Chrome Hexavalent adalah berbanding terbalik dengan kecendrungan penurunan pada grafik. Efisiensi Penyisihan yang cukup baik ialah rata-rata 98,5\% pada jumlah massa koagulan Carsul 5 gram. Berdasarkan data yang telah di hasilkan rata-rata efisiensi penyisihan kadar Chrome Hexavalent yang di hasilkan berkisar antara 89,25\% hingga 98,5\% hal tersebut dapat dikatakan semua variasi pelakuan yang diberikan cukup efisien untuk menurunkan kadar Chrome Hexavalent Pada air limbah tambang nikel PT. Vale Indonesia, Tbk.

\section{Pengaruh Lama Waktu Pengadukan Terhadap Efisiensi Penyisihan Chrome Hexavalent Dalam Air Limbah Tambang Nikel}

Variasi waktu yang di gunakan untuk perlakuan pada penelitian ini sebanyak empat variasi yaitu 20 detik, 30 detik, 60 detik, dan 90 detik. hal tersebut hampir sama dengan penentuan waktu yang dilakukan pada panelitian Wirani., dkk. (2011). Variasi waktu pengadukan (30, 60, 120 detik) dan kecepatan putaran $(170,240 \mathrm{rpm}$ ) dilakukan pada seri jar-test yang berbeda. Parameter yang diukur adalah sisa kekeruhan effluent hasil jar-test. 


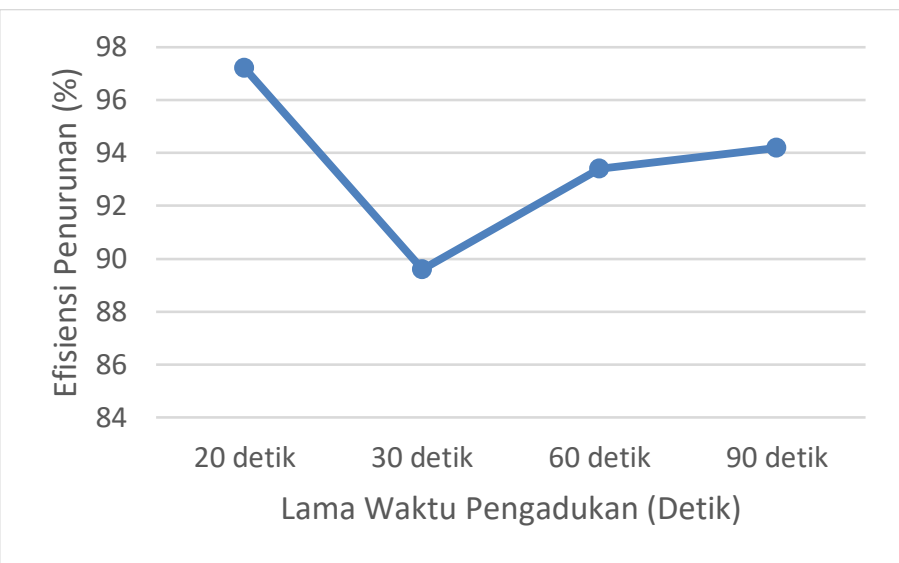

Gambar 2. Grafik hubungan antara lama waktu pengadukan dengan efisiensi penyisihan Chrome Hexavalent

Berdasarkan grafik lama waktu pengadukan dapat di perhatikan bahwa rata-rata efisiensi penyisihan kadar Chrome Hexavalent yang dihasilkan berkisar antara 91,8\% hingga 97,2\% hal tersebut dapat dikatakan semua variasi pelakuan yang diberikan cukup efisien untuk menurunkan kadar Chrome Hexavalent Pada air limbah tambang nikel PT. Vale Indonesia, Tbk.

\section{PENUTUP}

\section{Kesimpulan}

1. Kadar Chrome Hexavalent yang terkandung didalam air limbah hasil produksi industri tambang nikel PT. Vale Indonesia, Tbk ialah $0,2 \mathrm{ppm}$, tidak memenuhi baku mutu berdasarkan PERMENLH-RI di Nomor 5 Tahun 2014 sebesar 0,1ppm.

2. Massa koagulan memberikan pengaruh positif dalam proses penyisihan Chrome Hexavalent dalam air limbah tambang nikel PT. Vale Indonesia, Tbk. massa koagulan yang paling efektif adalah 5gram dengan rata-rata efisiensi penyisihan sebesar $98,5 \%$.

3. Lama waktu pengadukan juga memberikan pengaruh positif dalam proses penyisihan Chrome Hexavalent dalam air limbah tambang nikel PT. Vale Indonesia, Tbk. lama waktu pengadukan optimum adalah 20 detik dengan rata-rata efisiensi penyisihan sebesar 97,2\%.

\section{Saran}

1. Sebaiknya perusahaan khususnya yang memilik zat sisa berupa Carsul dapat di manfaatkan kembali agar tidak menjadi zat pencemar pada lingkungan.

2. Agar kiranya perusahaan-perusahaan dapat mengembangkan lebih lagi untuk Carsul ini bisa menjadi suatu nilai yang lebih berharga atau memiliki nilai ekonomis.

3. Adanya penelitian lanjutan yang dapat menjadikan Carsul sebagai bahan dasar untuk menghasilkan inovasi baru tanpa merusak lingkungan.

\section{DAFTAR PUSTAKA}

Astutia, R. F. (2020). Analysis of Chromium (VI) Concentration in the Area Around the Wastewater Treatment Plant at the Batik Factory. J. Xi'an Univ. Archit. Technol, 12, 1703-1709.

Blessing, T., Hendriyanto, O., Hidayah, E. N., \& Artyani, A. (2020). Application of Thomas Model to Determine the Capacity of Bintaro Fruit Shell Adsorbent. Nusantara Science and Technology Proceedings, 107-111.

Fasya, A. H. Z. (2018). The incidence of dermatitis analysis based on individual characteristics of metal plating workers in Sidoarjo. Jurnal Kesehatan Lingkungan, 10(2), 149-158.

Fitriyanto, N. A., Sari, A. K., Prasetyo, R. A., \& Kurniawati, N. (2021, May). Usage of Fenton Reagent in Local Tannery Wastewater Bioremediation. In IOP Conference Series: Earth and Environmental Science (Vol. 757, No. 1, p. 012033). IOP Publishing. 
Pemanfaatan Limbah Carsul Sebagai Koagulan Untuk Menurunkan Konsentrasi Chrome Hexavalent Dalam Air Limbah Industri

Nikel.

Muhammad Muzammil Ikmal, Mery Selintung, dan Rosalinda Ibrahim

Lestari, S., Dewi, R. S., \& Wibowo, E. S. (2019). Biosorption chrome (Cr) and dyes using biosorbent in the modified tea bag. Journal of Microbial Systematics and Biotechnology, 1(1), 38-43.

Nurani Asiah Zamil, N. (2021). EFEKTIFITAS PENURUNAN KADAR KROM (Cr) DALAM LIMBAH ANALISIS Chemical Oxygen Demand (COD) DENGAN MENGGUNAKAN ADSORBEN KARBON AMPAS THE (Doctoral dissertation, Universitas Sahid Jakarta).

Palippui, H. (2020). ANALISA PENANGGULANGAN SAMPAH PLASTIK DIPESISIR WILAYAH PANTAI UJUNG SUSO DENGAN MENGGUNAKAN MEDIA BUANGAN LIMBAH KAWAH GALIAN TAMBANG NIKEL SOROAKO. SENSISTEK: Riset Sains dan Teknologi Kelautan, 83-87.

Vale. 2017. Waste Management And Processing http://www.vale.com/indonesia/en/sustainability/nickel-for-life/pages/effluent.aspx (21 Mei 2021).

Said, N. I. (2018). Metoda penghilangan logam berat (As, Cd, Cr, Ag, Cu, Pb, Ni dan Zn) di dalam air limbah industri. Jurnal Air Indonesia, 6(2).

Winarni, dkk. 2011. Pengaruh Pengadukan Pada Koagulasi Menggunakan Alum. Jurusan Teknik Lingkungan. Universitas Trisakti. 